\title{
Perspectiva estética e sociopoética do cuidar de pessoas com sofrimento psíquico: apropriação do Tidal Model
}

\author{
An esthetic and sociopoetic perspective on caring for people with mental disorder: \\ appropriating the Tidal Model
Perspectiva estética y sociopoética del cuidar de personas con sufrimiento psíquico: apropiación del Tydal Model

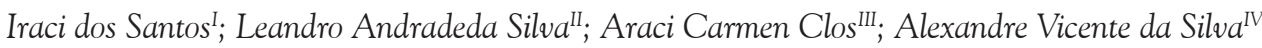

\begin{abstract}
RESUMO: Questiona-se como construir uma perspectiva estética e sociopoética do cuidar de pessoas com sofrimento psíquico, considerando o Tidal Model. Objetivou-se delinear uma perspectiva de cuidar em enfermagem fundamentada nos valores essenciais propostos por Phil Baker nesse modelo. Buscou-se, sem sucesso, em bases de dados, produção sobre essa teoria, no idioma português, trabalho completo de enfermagem disponível online. Utilizou-se o livro Modelos y teorias en enfermería, publicado em 2011, em inglês e espanhol. Os conceitos e ideias do autor dessa teoria possibilitaram vincular os princípios da Sociopoética à compreensão dos valores essenciais desse modelo, que remete às ações próprias da equipe de cuidados qualificados. Respondeu-se à questão inicial, com alcance do objetivo formulado, mediante a proposição de uma perspectiva estética e sociopoética do cuidar, fundamentada nos 10 compromissos dessa teoria. Compete aos profissionais de enfermagem promover uma interação cuidadosa e sensível com as pessoas, num espaço onde o cuidar é algo sagrado. Palavras-Chave: Enfermagem; teoria de enfermagem; saúde mental; perspectiva estética.
\end{abstract}

\begin{abstract}
It is asked how an aesthetic and sociopoetic perspective on caring for people with mental suffering can be constructed on the basis of the Tidal Model. The aim was to outline a perspective on nursing care grounded in the core values proposed by Phil Barker in the Tidal Model in nursing. A search in databases for full-length nursing studies this theory, published and available online in Portuguese, was unsuccessful. The book Modelos y teorías en enfermería, published in 2011, in English and Spanish. The concepts and ideas of the author of this theory made it possible to link the principles of Sociopoetics to an understanding of the essential values of this model, which relates to actions proper to a skilled care team. Thus the initial question was answered, and the goal achieved, by the proposal of an aesthetic and sociopoetic perspective on caring, based on the 10 commitments of the theory. It is up to professional nurses to foster sensitive, careful interaction with people in a place where caring is sacred.
\end{abstract}

Keywords: Nursing; nursing theory; mental health; aesthetic perspective.

RESUMEN: Se indaga acerca de la construcción de una perspectiva estética y sociopoética del cuidar de personas con sufrimiento psíquico, considerando el Tidal Model. Se objetivó delinear una perspectiva de cuidar en enfermería fundamentada en los valores essenciales propuestos por Phil Barker en esa teoría. Se buscó, sin suceso, en bases de datos, produccíon sobre esa teoría, en português, trabajo completo de enfermería disponible online. Se utilizó el libro Modelos y teorias en enfermería, publicado en 2011, en inglés y español. Los conceptos y ideas del autor de esa teoria posibilitaron vincular los princípios de la Sociopoética a la comprensión de los valores esenciales de ese modelo, que remete a las acciones propias del equipo de cuidados calificados. Se respondió a la pregunta inicial, con alcance del objetivo formulado, a través de una proposición de la perspectiva estética y sociopoética del cuidar, fundamentada em los 10 compromisos de esa teoría. Compete a los profesionales de enfermería promover una interacción cuidadosa y sensible con las personas, en un espacio donde el cuidar es algo sagrado. Palabras-Clave: Enfermería; teoría de enfermería; salud mental; perspectiva estética.

\section{INTRODUÇÃO}

A produção científica em enfermagem requer inovações e tecnologias adequadas para desenvolver ações indispensáveis ao bem-estar das pessoas nas diversas situações de sobrevivência neste mundo, consigo e com os outros. Seus profissionais convivem com desafios oriundos da complexidade, vulnerabilidade, fragilidade

'Enfermeira. Doutora em Enfermagem. Professora Visitante do Departamento Fundamentos de Enfermagem e do Programa de Pós-Graduação da Faculdade de Enfermagem da Universidade do Estado do Rio de Janeiro. Brasil.E-mail: iraci.s@terra.com.br

IIEnfermeiro. Doutorando em Enfermagem do Programa de Pós-Graduação da Faculdade de Enfermagem da Universidade do Estado do Rio de Janeiro. Professor da Universidade Castelo Branco. Rio de Janeiro, Brasil. E-mail: proflandrade@gmail.com

IIIEnfermeira. Mestre em Filosofia. Professora Assistente do Departamento Fundamentos de Enfermagem da Faculdade de Enfermagem da Universidade do Estado do Rio de Janeiro. Brasil. E-mail:araciclos@yahoo.com.br.

hh Enfermeiro. Terapeuta floral. Mestre em Enfermagem. Professor Assistente do Departamento Enfermagem Médico-Cirúrgica da Faculdade de Enfermagem da Universidade do Estado do Rio de Janeiro. Brasil. E-mail: alexvicente@gmail.com 
e/ou potencialidade do viver do indivíduo que enfrenta dificuldades, ansiedades, e estresses inerentes do mundo contemporâneo.

Tais desafios conduzem aos questionamentos sobre a aplicação dessa produção, a exemplo das teorias que propõem modelos conceituais, e ressignificam paradigmas de cuidar de séculos passados, porém vigentes neste milênio, a exemplo da área de psiquiatria e saúde mental $(\mathrm{SM})^{1}$.

O cuidar qualificado remonta ao autoconhecimento do profissional e ao reconhecimento dos clientes, respeitando sua singularidade, dignidade e necessidades humanas na integralidade de suas dimensões corporais física, mental e espiritual ${ }^{2}$. Pois a enfermidade, em si, não se restringe apenas ao corpo físico e social. Na complexidade existencial, vivemos situações que nos permitem chorar de alegria, enlouquecer de felicidade, mentir para ser feliz, maltratar a quem se ama, ocultar a revolta, a solidão, a tristeza, a infelicidade e trabalhar sem descanso, usando a capa da reconhecida loucura.

Pesquisadores se preocupam com essas situações, tal qual Phil Barker ${ }^{3-5}$, que em sua curiosidade, se questionava sobre aspectos relacionados ao trabalho que desenvolvia com pessoas em sofrimento psíquico (SP): o que é ser uma pessoa? Qual é o objetivo do trabalho da enfermagem com pessoas em sofrimento psíquico (SP)? Para que servem as ações de enfermagem? Partindo desses questionamentos, ele investiu sua intelectualidade na construção de um modelo de cuidados de enfermagem em SM.

Pensando nesse modelo, reflete-se sobre um objeto de estudo contribuinte para a qualificação de enfermeiros atuantes na enfermagem psiquiátrica e SM, visando ações de cuidados específicos junto aos clientes internados em instituição dessa área, além dos clientes atendidos em ambulatórios e centros de saúde mental na comunidade.

Justifica-se o objeto de estudo - Perspectiva estética e sociopoética6 do cuidar de pessoas com sofrimento psíquico: apropriação do Tidal Mode ${ }^{3,4}$, pelo fato dele valorizar a relação interpessoal com enfoque na narrativa da pessoa expressando sua história de vida e do adoecimento. Para esse teórico, um objetivo do cuidar em enfermagem é o autoconhecimento do profissional e o conhecer a pessoa/ cliente para juntos construírem e realizarem o cuidado em $\mathrm{SM}^{2-5}$.

No desenvolvimento de um pescurso, estratégia utilizada na pesquisa sociopoética, constatou-se a dificuldade dos alunos da disciplina de psiquiatria e SM delinearem um perfil imaginário do indivíduo com SP. Portanto, reflete-se: sem conhecer seu futuro cliente, como o estudante e/ou o profissional pode cuidar dele?

Justifica-se a inserção da sociopoética na perspectiva estética ${ }^{6}$, visto a semelhança dos princípios filosóficos, conceitos e definições e compartilhamento do poder/saber ${ }^{5-7}$, de ambas as teorias, que valorizam a pessoa a partir de seu discurso e seus direitos para viver e conviver, considerando sua dignidade humana.

Assim, questiona-se: como construir uma perspectiva estética e sociopoética de cuidar de pessoas com sofrimento psíquico, a partir do Tidal Model?

Teve-se como objetivo propor uma perspectiva de cuidar em enfermagem fundamentada nos valores essenciais propostos por Phil Barker no Tidal Model.

Pressupõe-se que a apropriação desse modelo seja necessária para a construção dessa perspectiva que se aproxima da sociopoética como prática de cuidar/ educar $^{2,5-7}$, pois apresenta princípios de cuidados de enfermagem, serve de guia para a atuação profissional, tem aplicação universal, e se fundamenta nas necessidades da pessoa com $\mathrm{SP}^{2,5}$.

\section{Referencial Teórico - Metodológico}

O criador desse modelo refletiu sobre a necessidade de os profissionais de enfermagem delegarem poderes aos clientes sob seus cuidados, ao valorizarem suas histórias de vida e a experiência da loucura, em busca da recuperação da SM, considerando aspectos pessoais e espirituais.

A filosofia oriental, pautando-se nas idéias de Shoma Morita (psiquiatra japonês) e nas Teorias do Relacionamento Interpessoal de Sullivan e de Peplau; as ideias da anti-psiquiatria de Szasz, o pensamento de recuperação da sanidade de Podvoll e da terapia focada em soluções de Shazer dominam os estudos de Phil Barker, visto sua crença na capacidade de viver e de crescer mediante crises vivenciadas ao longo da existência. Refletindo sobre as águas do mar, ele afirmou ser necessário ajudar criativamente as pessoas a cruzarem as águas turbulentas, comparáveis ao SP, ressaltando a importância de os enfermeiros se relacionarem diretamente com elas ${ }^{3,4}$.

Esse modelo extrai sua metafora filosófica central da Teoria do Caos, na qual a imprevisibilidade da natureza assemelha-se à vida humana, comparando-a ao fluxo de poder da água, pois as marés realizam um movimento de ir e $\operatorname{vir}^{3,4}$. Nesse, as forças da água se misturam sem padrões repetitivos, porém, com padrões delimitados 3,4 .

O desenvolvimento da compreensão das necessidades da pessoa possibilita um trabalho cooperativo e a construção de uma relação terapêutica entre o cliente e o profissional de saúde; favorece métodos de delegação ativa de poder, nos quais os enfermeiros atuam como educadores, no centro da intervenção interdisciplinar, buscando a resolução de problemas e a promoção da SM, mediante a valorização e a manutenção do foco na narrativa do cliente ${ }^{3,4}$. 
É uma filosofia para a recuperação da SM, diferenciada do modelo vigente de atendimento ou tratamento do TM. Uma visão específica de mundo, que auxilia o enfermeiro a compreender o que é SM na perspectiva do cliente e como ajudá-lo na sua recuperação, compreendendo a vida humana nas dimensões físicas, emocionais, intelectuais, sociais e espirituais ${ }^{2-5}$.

Tais aspectos fenomenológicos permeiam o Tidal Model, enfocando a vivência do indivíduo, assim como as suas singulares histórias de vida, repletas de metáforas e intervenções narrativas ${ }^{3-5}$.

Seu criador utiliza o conceito de uso terapêutico do eu, proposto por Travelbee (Modelo de Relações entre Seres Humanos) $)^{8}$, que auxilia o alcance do objetivo da enfermagem, e os três elementos/conceitos que sustentam o Tidal Model: as Relações Interpessoais de Peplau'; Enfermagem psiquiátrica e saúde mental; Delegação de poder nas relações interpessoais ${ }^{3,4}$.

\section{MÉTodo}

Por situar-se no século 21, buscou-se em bases de dados publicações sobre o Tidal Model, considerando: período de 2001 a outubro de 2014, idioma português, trabalho completo de enfermagem disponível online. A escolha desse idioma visou descobrir se esse modelo era conhecido na área de enfermagem brasileira.Não foram encontradas publicações atendendo aos critérios selecionados. Então, foram utilizados os livros Modelos y teorías enfermeira ${ }^{3}$, sétima edição e o Nursing theorist and their work ${ }^{4}$, oitava edição, de 2011 e 2014.

Para compreender a apropriação desse modelo na construção teórica da perspectiva estética e sociopoética do cuidar em enfermagem em saúde mental, descreve-se as reflexões, ideias e concepções de Phil Barker.

\section{Conceitos pilares para a construção da teoria}

- Enfermagem - Profissão que realiza trocas constantes com outras profissões e áreas do conhecimento. Constructo social e não somente uma profissão. O que define a enfermagem mundialmente é a construção social e o papel da enfermeira ${ }^{3,4}$. Desenvolve um trabalho educativo, constituindo-se como atividade interpessoal, humana e duradoura, centrada no crescimento pessoal através de trocas.

Barker amplia as concepções de Peplau, definindo o objetivo da enfermagem com a palavra de derivação grega thephotaxis, que significa promover o crescimento e desenvolvimento pessoal ${ }^{9}$. Propôs uma distinção de enfermagem psiquiátrica (EP) para a enfermagem em SM: na EP, o trabalho do profissional desta área visa remediar e reduzir a sintomatologia apresentada pelo cliente; na SM, o trabalho do enfermeiro auxilia a pessoa a desenvolver maneiras de crescer e desenvolver-se, indo além do que vive atualmente, conseguindo compreender e superar seus atuais problemas psiquícos ${ }^{3,4}$.
- Pessoa - Caracteriza a visão fenomenológica da experiência a partir das narrativas de suas história de vida. Elas são filósofas de suas vidas, pois o viver produz significados e valores singulares acerca do mundo e de sua relação com ele. Os profissionais de enfermagem devem ser capazes de apreciar o mundo desde a sua perspectiva até a do outro. As pessoas são a sua história, o sentido do eu, sua relação com o mundo de experiências. Estão intrinsecamente interligadas nas histórias de suas vidas ${ }^{3,4}$.

- Saúde - Capacidade de adaptar-se ao meio e as trocas. Englobaria o futuro, incluindo os recursos internos para o viver saudável. Resulta do autoconhecimento, da autodisciplina e dos recursos internos de cada pessoa no controle de seus ritmos, desde a alimentação até aspectos sexuais. A personalidade humana e suas fragilidades resultam das experiências de dor, enfermidades e de mortes, como parte integral da vida ${ }^{3,4}$.

A saúde é um todo e resultante da vivência do indivíduo, inclusive nos contextos culturais, sociais, econômicos, sociais e espirituais ao longo da vida. A partir de uma concepção holística, as pessoas atribuem significados individuais à saúde e à enfermidade. Cabe aos enfermeiros conhecer seus clientes considerando esses diferentes aspectos, para utilizá-los como recursos terapêuticos ${ }^{3,4}$.

- Entorno - Meio social onde as pessoas viajam por seu oceano de experiências e o enfermeiro cria espaços para o crescimento e desenvolvimento pessoal. As relações terapêuticas buscam o elo do individuo com o seu entorno. Os problemas humanos do cotidiano podem se derivar de complexas interações da pessoa com eles, onde o caos pode se instalar. No entorno, estão as áreas vitais do cotidiano, tais como a ocupação, o ócio, o sentido de lugar e o pertencimento ${ }^{3,4}$.

\section{Conceitos principais e definições}

- O objetivo terapêutico do cuidado está na comunidade. A vida cotidiana da pessoa é um oceano de experiências e as crises psiquiátricas encontram-se entre coisas que podem afundá-la. O objetivo do cuidado em SM é devolver às pessoas esse oceano de experiências possibilitando-lhes continuar sua recuperação ${ }^{3,4}$.

As trocas são um processo contínuo e as pessoas trocam constantemente. Isso pode ocorrer para além de sua consciência. Um dos principais objetivos é ajudá-las a desenvolver uma consciência das pequenas mudanças, as quais têm um grande efeito sobre as suas vidas ${ }^{3,4}$.

- Tais mudanças integram o processo de cuidar, contudo os indivíduos têm seu próprio poder. Devese auxiliá-los nesse empoderamento para a obtenção do controle de suas vidas de maneira construtiva ${ }^{3,4}$.

- O profissional e o cliente estão unidos como membros de um corpo de ballet. Isso significa que nos encontros genuínos eles devem se cuidar juntos e não o cuidar uni-pessoal ${ }^{3,4}$. 


\section{Os três domínios do Tidal Model - O modelo voltado para a pessoa}

O modelo está representado: eu, os outros e o mundo. O domínio é uma esfera na qual o indivíduo vivencia aspectos da vida privada e pública. Lugar onde ele vive, sua casa ${ }^{3,4}$.

- Domínio do eu -Lugar privado, nele se guardam os pensamentos, crenças, valores, ideias e somente o vivente o conhece. Nele se sofre o primeiro mal-estar, chamado de doença mental. Muitas pessoas mantém em segredo boa parte de seu mundo privado revelando apenas o que desejam. Esse é o motivo que as tornam um mistério para os outros ${ }^{3,4}$.

Nesse domínio, o enfermeiro auxilia a pessoa a sentir-se mais segura, a enfrentar os seus medos e o que a faz sofrer. Seu principal objetivo é possibilitar, junto ao sujeito, criar o que foi denominado plano de segurança pessoal ${ }^{3,4}$. Um trabalho base para desenvolver um programa de autoajuda.

- Domínio do mundo - Onde a pessoa compartilha experiências do domínio do eu com outras pessoas em seu meio social. Quando se compartilha pensamentos, anseios, visões de mundo. Caracteriza o centro dos esforços do profissional para compreender o cliente e seus problemas. Torna-se possível mediante uma concepção holística. Tenta-se ajudá-lo a identificar problemas específicos que atrapalham sua vida diária e, nesses casos, utilizam-se sessões individuais ${ }^{3,4}$.

- Domínio dos outros - Nele se encontram os cuidados profissionais e demais maneiras de apoio. Focalizamse prioritariamente grupos de atendimentos; neles é possível compartilhar informações e buscar soluções. Participando de grupos, a pessoa desenvolve uma consciência de valor do apoio social que pode dar e receber dos demais. Essa é a base para a compreensão da pessoa e do valor do apoio mútuo que estará acessível na vida diária ${ }^{3,4}$.

\section{Resultados e Discussão}

Descreve-se a proposição de uma perspectiva estética e sociopoética do cuidar em enfermagem, a partir da apropriação do Tidal Model.

A sua leitura atenta e reflexiva possibilitou o vínculo dos princípios filosóficos da Sociopoética à compreensão dos 10 compromissos reveladores da essência do valor do referido modelo, que remete às ações passíveis de execução por equipe de cuidados qualificados. Assim, responde-se à questão inicial, e demonstra-se o alcance do objetivo formulado, com uma proposta da perspectiva estética e sociopoética fundamentada nos compromissos, descritos a seguir.

- As ações de ajuda à pessoa com sofrimento psíquico se iniciam com a valorização de sua fala, na descrição de sua história de vida, incluindo o relato do sofrimen- to, expectativas e esperanças que demarcam o início e o fim de todo este processo de cuidado. Desse modo, na prática de cuidar/educar sociopoética, os sujeitos se sentem livres, empoderados para pronunciar a sua vida no mundo ${ }^{7-10}$.

Alerta-se sobre os relatos na terceira pessoa, relatos profissionais, que podem não expressar exatamente a história do sujeito, mas sim a percepção dos profissionais. Por isso, os relatos do cliente sobre a sua história e a percepção dos profissionais de saúde são analisados conjuntamente, visando à fidelidade desses depoimentos, tal qual acontece no método sociopoético ${ }^{11}$.

- Respeitar a linguagem. As pessoas descrevem suas histórias de vida de forma única, relatam fatos que somente elas conhecem. A compreensão dessa forma peculiar de expressão é o meio que ilumina o caminho de recuperação. Incentiva-se que elas falem, utilizando suas próprias palavras, peculiares a sua maneira de se expressar perante ao mundo. Um princípio da Sociopoética, respeitar a linguagem do sujeito, é considerar seus valores, crenças e saberes, pois eles são iguais em direito, quer sejam orais, gestuais e/ou através de práticas artísticas ${ }^{10,11}$.

Comumente os profissionais registram as falas dos clientes através de termos técnicos, utilizados pela psiquiatria. $\mathrm{O}$ Tidal Model propõe que se observe a linguagem natural da pessoa, sendo esta uma maneira de respeitá-la. Similarmente, no educar/ cuidar, a Sociopoética valoriza as formas de expressão das pessoas, considerando suas cultura, tradições e ancestralidade $2,6,10,11$.

- Desenvolver uma curiosidade original. O cliente escreve sua história, tal como um livro fechado. É impossível conhecer a experiência de outra pessoa. Cabe aos enfermeiros, e demais profissionais de SM, demonstrar verdadeiro interesse pelas histórias dos clientes. Assim, é possível entendê-los melhor ${ }^{12}$. Sobretudo, se através de uma postura empática e de uma escuta sensível.

Geralmente os profissionais se interessam apenas pelo o que faz o indivíduo sofrer, realizando avaliações que buscam sinais e sintomas. Quando se revela uma curiosidade genuína, demostra-se um interesse pela pessoa e sua experiência única. Deve-se perceber características que podem ser comuns a outros sujeitos em SP. Entretanto, importa perceber e compreender o que é singular. No cuidar sociopoético, prioriza-se o reconhecimento da dignidade humana do cliente, considerando sua integralidade e singularidade ${ }^{2,6,10}$.

- Tornar-se aprendiz. O indivíduo é o especialista mundial de sua história de vida. Os profissionais podem se apropriar dessas histórias de maneira respeitosa, visando possibilitar um aprendizado único com cada pessoa e sua história. É o cliente quem indicará o caminho do que deve ser feito ${ }^{12}$. Assim como ac- 
ontece na revelação de saberes ocultos, sentimentos recalcados são desvendados quando se dá vez e voz aos sujeitos, nas oficinas sociopoéticas ${ }^{13,14}$.

Ninguém é capaz de conhecer a real experiência de um indivíduo. Os profissionais frequentemente acham que sabem muito mais sobre uma pessoa do que ela própria. Barker questiona - como se pode saber mais sobre uma pessoa, que pouco se conhece, do que o próprio individuo que conhece a si próprio. Leva-se tempo para perceber que as pessoas jamais serão capazes de conhecer o outro em plenitude ${ }^{12}$.

- Usar ferramentas disponíveis. A história da pessoa revela estratégias que funcionaram no passado e que podem funcionar no futuro. Entretanto, os recursos internos da pessoa são a principal para desbloquear ou criar a história de recuperação. As ferramentas utilizadas pelos profissionais são expressas habitualmente através de ideias como a prática baseada em dados científicos. Descrever o que funciona em outras pessoas, potencialmente, pode ser útil, desde que o conjunto de ferramentas esteja disponível ${ }^{12}$.

- Trabalhar um passo adiante. O profissional que cuida e a pessoa cuidada trabalham juntos em prol da recuperação da SM. Eles decidem sobre o próximo passo a ser dado. Fazer isso é crucial e revela o poder de troca, apontando o objetivo final da recuperação. Afirma-se que toda viagem de milhares de quilômetros começa com um primeiro passo. Qualquer viagem se inicia pela imaginação. Depende-se disso para prever o que será realizado. Trabalhar um passo à frente junto à pessoa; planejar juntos o passo de agora, e pensar qual será o próximo $3,4,12$.

- Dar tempo ao tempo. Nada é mais valioso do que o tempo que a pessoa e o cuidador passam juntos. Frequentemente o profissional se queixa de não ter tempo para trabalhar de maneira construtiva com as pessoas. Ele precisa notar que o tempo é dele e de outra pessoa, sendo destinado à relação interpessoal construtiva, valioso para ambas as partes ${ }^{3,4,12}$.

- Revelar a sabedoria pessoal. Somente a pessoa se autoconhece. Escrevendo sua história ela revela maior repertório de sabedoria. Comumente não encontra palavras para expressar plenamente sua multiplicidade, inefabilidade e complexidade. Evocar metáforas pessoais para transmitir suas experiências é importante. Atividade fundamental do profissional é auxiliá-la a revelar, obter, valorizar a sua própria sabedoria; algo possível para apoiá-la durante a sua recuperação $0^{3,4}$.

Um dos princípios da Sociopoética é a noção de devir, o qual sugere a multiplicidade heterogênea de cada ser. É algo que escapa a categorização socialmente produzida e revela o singular de cada um $^{11}$.

- Compreender que as mudanças são constantes, inevitáveis. Compõem a história comum de todos; seu crescimento é opcional. Necessita-se tomar decisões e eleger o que levará a pessoa ao crescimento. A tarefa do profissional é reconhecer que essas possibilidades de mudanças e de apoio, na tomada de decisões, importam para a pessoa superar o mal-estar em direção à sua recuperação $0^{3,4}$.

- Ser transparente. Se o profissional e a pessoa em sofrimento formam uma equipe, devem baixar suas defesas e se abrirem para possíveis mudanças. Ao escrever a história, a caneta do profissional pode tornar-se uma arma; corre o risco de inibir, restringir e delimitar as escolhas vitais do indivíduo. Os profissionais têm posição privilegiada; devem conquistar a confiança e ser transparentes, possibilitando que a pessoa entenda o que está acontecendo e porque está ali. Valorizar a linguagem e construir planos de cuidados junto com os sujeitos ${ }^{3,4,12}$.

\section{Conclusão}

Vê-se que esse modelo orienta o profissional na busca de respostas, tentando satisfazer as necessidades individuais e contextuais da pessoa, que está sob sua orientação. Nele, o sofrimento psiquíco é descrito com termos metafóricos. $\bigcirc$ criador emprega metáforas universais e culturalmente significativas associadas ao poder das águas do mar, para representar aspectos conhecidos do sofrimento humano. As águas são a metáfora central vivida pelas pessoas, e os cuidados de enfermagem as modelam.

Barker evidencia um grande interesse pela experiência humana de sofrimento psíquico.

Para ele, uma das características da prática de enfermagem é a utilização de possibilidades de relações colaborativas com usuários de serviços de saúde mental.

Compete, aos profissionais de enfermagem, realizar uma interação cuidadosa e sensível com as pessoas em um espaço onde o cuidar é algo sagrado.

\section{REFERÊNCIAS}

1.Silva LA, Gomes AMT, Oliveira DC, Souza MGG. Social representations of aging in institutionalized psychiatric patients. Esc Anna Nery. [site da Internet] 2011 [cited in 2014 Out 02] 15: 124-31. Disponível em: http://www. scielo.br/scielo.php?script $=$ sci_arttext $\&$ pid $=S 1414$ $81452011000100018 \& \operatorname{lng}=\mathrm{en}$.

2.Santos I, Caldas CP, Gauthier J, Erdmann AL, Figueiredo NMA. Caring for the whole person: the contributions of aesthetics/sociopoetics perspectives to the field of nursing. Rev enferm UERJ. [site da Internet] 2013 [cited in 2014 Nov 02]. 21: 4-9. Disponível em: http:// www.e-publicacoes.uerj.br/index.php/enfermagemuerj/ article/view/3967/2750

3.Brookes N. Barker P: El modelo de la marea en la recuperación de la salud mental. 7 ed. In: Tomey AM, Alligood MR. Modelos y teorías en enfermería. Barcelona (Es): Elsevier; 2011. 
4.Brookes N. The Tidal Model in the mental health recuperation. 8th ed. In: Tomey AM, Alligood MR. Nursing theorists and their works. New York (EUA): Elsevier; 2014.

5.Barker PJ. The Tidal Model: developing a person - centred approach to psychiatric and mental health nursing. Perspectives in psychiatric care. [site da Internet] 2001 [cited in 2014 Oct 22] 37(3): 79-87. Available in: http:// www.ncbi.nlm.nih.gov/pubmed/15521295

6.Santos I, Figueiredo NMA, Erdmann AL, Rodrigues BMRD, Berardinelli LMM. Perspectiva estética: filosofia e apropriação para o cuidado de enfermagem. In: Figueiredo NMA, Machado WCA. Tratado de cuidados de enfermagem médico-cirurgica. São Paulo: Roca; 2012. p. 93-103. 7.Gauthier J. O oco do vento: metodologia da pesquisa sociopoética e estudos transculturais. Curitiba (PA): Editora CRV; 2012.

8.Tomey AM, Alligood MR. Modelos y teorias en enfermería. 6a ed. Barcelona (Es): Elsevier; 2005.

9.Pokorny ME. Teorias en enfermería de importância histórica. In: Tomey AM, Alligood MR. Modelos y teorias en enfermería. 7ํㅡㄹ. ed. Barcelona (Es): Elsevier;2011. p.54-5. 10.Santos I, Silva LA, Gauthier J, Guerra RGM. Con- tributions of social poetics on the scientific production regarding nursing care: an integrative literature review. Rev Eletr Enf. [site Internet] 2013 [cited in 2014 Oct 03];15:243-52. Available in: http://dx.doi.org/10.5216/ ree.v15i1.20888.

11.Santos I, Gauthier J, Petit SH, Figueiredo NMA. Prática da pesquisa em ciências humanas e sociais: abordagem sociopoética. São Paulo: Atheneu; 2005.

12.Barker P, Buchanan-Barker. The Tidal Model: a guide for mental health profissionals. New York: BrunnerRoutledge; 2005.

13.Salgado APA, Santos I, Progianti, JM. Disclosing actives archetype on the woman existence on the hospital delivery: sociopoetic study. Rev Pesq: Cuidado é Fundamental (Online). [site da Internet] 2013 [cited in 2014 oct 14]: 3332-5. Disponível em: file://Users/leandroandrade/Downloads/1930-13778-1-PB\%20(1).pdf 14.Santos I, Jesus PBR, Brandão ES, Oliveira EB, Nascimento AV. Repercussões do acometimento cutâneo na vida das pessoas: sociopoetizando a autoimagem e a autoestima. Rev enferm Uerj. [site da Internet] 2014 [citado em 01 out 2014] 22: 157-62. Disponível em: http://www.facenf.uerj.br/v22n2/v22n2a02.pdf 